\title{
Evaluation of three patient reported outcome measures following operative fixation of closed ankle fractures
}

\author{
Andrew M. Garratt ${ }^{1 *}$, Markus G. Naumann², Ulf Sigurdsen ${ }^{3}$, Stein Erik Utvåg ${ }^{3,4}$ and Knut Stavem ${ }^{4,5,6}$
}

\begin{abstract}
Background: Several patient reported outcome measures (PROMs) are available for assessing the outcomes of ankle fracture but few have been compared for recommended measurement properties. This study compares the measurement properties of the Lower Extremity Function Scale (LEFS), Olerud Molander Ankle Score (OMAS) and Self-Reported Foot and Ankle Score (SEFAS) following ankle surgery.

Methods: The retrospective cohort study included 959 patients aged 18 years and over who underwent surgical treatment (ORIF) for unstable and closed ankle fractures in SE Norway. The PROMs were included in a postal questionnaire sent to patients' homes in 2015, three years after surgery. Missing data, structural validity, internal consistency, test-retest reliability and validity were assessed.

Results: Confirmatory factor analysis results showed model fit for the SEFAS and a bi-dimensional LEFS with scales of easy and difficult items. The OMAS performed less satisfactorily. Cronbach's alpha and test-retest correlations ranged from 0.82 to 0.96 and 0.91 to 0.93 respectively. The smallest detectable differences for group and individual comparisons were 14.1 to 20.6 and 0.93 to 1.55; SEFAS performed best. As hypothesised, instrument scores were highly correlated and with those for the EQ-5D and SF-36 physical functioning. Mean imputation where half or more items are completed increased usable scores by $1.4-15.7 \%$ without affecting measurement properties.

Conclusions: The three instruments largely performed satisfactorily in relation to important measurement properties but the LEFS had evidence for two dimensions relating to easier and more difficult aspects of function. Mean imputation where half or more items are completed increased the number of usable responses for all three instruments. The three instruments represent different approaches to measuring outcomes and their content should be considered carefully when choosing between them. The SEFAS is designed for a range of foot disorders including ankle fractures and has the best measurement properties in this population.
\end{abstract}

Keywords: Ankle, Patient reported outcome measures, PROMs, PROs, Validity, Reliability

\section{Background}

Ankle fracture constitutes approximately $9 \%$ of all fractures, have an incidence of 122 per 100,000 people [1] and incidence requiring hospitalisation of 83 per 100,000 people [2]. Following a systematic review it was concluded that there was insufficient evidence as to whether conservative management or surgery gives the best long-term outcomes in adult patients [1]. Moreover,

\footnotetext{
* Correspondence: andrew.garratt@fhi.no

'Division for Health Services, Norwegian Institute of Public Health, Oslo, Norway

Full list of author information is available at the end of the article
}

the evidence derived from a systematic review of competing surgical technologies led to the conclusion that further evaluation, including greater consideration of long-term outcomes, was necessary [3].

Ankle fractures reduce quality of life and particularly in older people, may cause loss of independence. It is important that studies evaluating outcomes in these patients include valid and reliable patient reported outcome measures (PROMs) that reflect important concerns of patients [4]. There are a large number of ankle-specific PROMs [5] but few have been developed with the input of fracture patients or sufficiently evaluated

(c) The Author(s). 2018 Open Access This article is distributed under the terms of the Creative Commons Attribution 4.0 International License (http://creativecommons.org/licenses/by/4.0/), which permits unrestricted use, distribution, and reproduction in any medium, provided you give appropriate credit to the original author(s) and the source, provide a link to the Creative Commons license, and indicate if changes were made. The Creative Commons Public Domain Dedication waiver (http://creativecommons.org/publicdomain/zero/1.0/) applies to the data made available in this article, unless otherwise stated. 
for measurement properties [4]. Clinicians and researchers wishing to select an ankle specific PROM are faced with a confusing array of instruments with little information on measurement properties in ankle fracture patients. When a choice of instrument exists, the concurrent evaluation of their measurement properties in the patients and health care setting of interest is highly informative [6]. Systematic reviews of measurement properties are also informative, however, the two published reviews focus on ankle problems more generally [5] or ligament injuries [7].

The Lower Extremity Functional Scale (LEFS) [8], Olerud and Molander Ankle Score (OMAS) [9] and Self-Reported Foot and Ankle Score (SEFAS) [10] have been widely applied but have undergone limited testing for measurement properties in patients with ankle fractures. These three instruments represent different approaches to measuring outcomes in patients with ankle fractures; the LEFS focuses on lower limb, the OMAS is ankle fracture specific, and the SEFAS is foot and ankle specific. None of them have been tested for structural validity, which gives evidence supporting their scoring as unidimensional scales. This study compares important measurement properties of these instruments, including reliability and validity [11].

\section{Methods}

\section{Study population}

The retrospective cohort study included 959 patients who underwent surgical treatment (ORIF) for unstable and closed ankle fractures at two hospitals in SE Norway [12]. Patients were 18 years of age and over and treated in a three year period from January 1, 2009. They received a postal questionnaire that included LEFS, OMAS and SEFAS in January 2015; 299 respondents received a test-retest questionnaire at six weeks. Non-respondents received a reminder at four weeks.

\section{Patient-reported outcome measures}

Norwegian translation of the three instruments followed international guidelines [11] including two independent forwards and one independent backwards translations with a meeting to agree on the final Norwegian versions.

The LEFS comprises 20 items relating to physical function and daily activities with a five-point scale from 'extreme difficulty or unable to perform' to 'no difficulty' [8]. Items are summed to give a score from 0 to 80 where 80 is the best possible score. The mean of the completed items is used when up to four items are missing $[8,13]$ and normative data is available to aid the interpretation of LEFS scores [14]. Two studies have assessed the measurement properties of LEFS in patients with ankle fracture and there is evidence for reliability, validity and responsiveness in Australian patients [15] and in Finnish patients undergoing surgery due to musculoskeletal pathology of the foot and ankle [16].

The OMAS comprises nine items relating to symptoms, physical function and daily activities [9]. The response scales vary from binary to five-points with clinical scoring that reflects the level of disability for individual items. Item responses are summed to give a score from 0 to 100 with higher scores representing the best possible. The instrument has evidence for test-retest reliability and construct validity in patients with ankle fracture in Sweden [17] and Turkey [18].

The SEFAS comprises twelve items relating to pain, limping, swelling, use of orthotics and walking. The fivepoint scales reflect item content and sum to give a score from 12 to 60 where the former represents normal function $[10,19]$. The mean of the completed items is used when one item is missing. The instrument has not been evaluated solely in patients with ankle fracture but has evidence reliability, validity and responsiveness in Swedish patients with foot and ankle disorders undergoing surgery $[10,19]$. For purposes of comparison, scores for the LEFS and SEFAS are also presented on a 0 to 100 scale where higher scores represent the best possible.

Two generic instruments were also included in the questionnaire. The EQ-5D-3L includes five items with a three-point response scale which are scored to give a single index [20]. The SF-36 physical function scale comprises ten items with a three-point scale which sum to a 0 to 100 scale where 100 is the best possible health [21].

\section{Statistical analysis}

The measurement properties tested and related terminology follow the COSMIN checklist [11]. Levels of missing data were assessed at the item and scale level with the latter also including imputation for missing data where half or more item responses were present. For comparison, all items were recoded from 0 to 4 where 4 is the best possible health.

Confirmatory factor analysis (CFA) with weighted least squares estimation was used to assess structural validity. Model fit was assessed with the comparative fit index (CFI), Tucker-Lewis Index (TLI) and root mean square error of approximation (RMSEA) [22-24]. The CFI and TLI should be greater than 0.90 and RMSEA between 0 . 06 and 0.08 for acceptable fit [24, 25]. Internal consistency was assessed using item-total correlation which should exceed 0.4 and Cronbach's alpha, which should exceed 0.7 and 0.9 for use in groups and individual patients, respectively [26]. The intraclass correlation coefficient was used for estimating reliability within a two-way mixed effects model with absolute agreement. Weighted kappa was used for assessing individual item reliability 
[27]. The standard error of measurement (SEM) and smallest detectable change (SDC) were calculated. The former is the square root of the total error variance. For individuals the SDC is $1.96 \times \sqrt{ } 2 \times$ SEM and for groups, the SDC for individuals is divided by $\sqrt{ } \mathrm{n}$ [26].

Hypothesis testing was used to assess the validity of the three ankle instrument scores through comparisons of those for the EQ-5D and SF-36 physical functioning and clinical variables. These instruments were included in previous tests of validity for the LEFS [13] and SEFAS [10] and continue to be the most widely evaluated and applied PROMs [6]. It was hypothesised that scores for the three instruments would be highly correlated over 0 . 7. High levels of correlation were expected with SF-36 physical functioning and particularly for the LEFS, given the overlap in content. The three instruments include items that overlap with two or more EQ-5D items and hence high levels of correlation were expected for EQ5D scores and the EQ-5D mobility item. Moderate levels of correlation in the range 0.5 to 0.7 were expected for the EQ-5D usual activities and pain items. Lower levels of correlation in the range 0.3 to 0.5 were expected for the EQ-5D self-care and anxiety/depression items. Lower levels of correlation under 0.3 were hypothesised for the clinical variables including ASA classification, BMI, duration of operation and fracture classification.

LISREL was used for the CFA and PASW Statistics 18. 0 was used for the remainder of the statistical analysis.

\section{Results}

\section{Study population}

The questionnaire was returned by 567 (59.1\%) patients. Table 1 shows the characteristics of respondents. There were $182(60.9 \%)$ respondents to the test-retest questionnaire.

\section{Statistical analysis}

Levels of missing data ranged from 1.2 to $6.2 \%$ across the three instruments (Table 2). Levels of missing data were highest for items assessing higher levels of function including 'hopping' and 'running' for LEFS and 'jumping' for OMAS. For the LEFS, the 'getting in and out of bath' had the highest level of missing data. Use of mean imputation for missing data increased the number of useable scores by 1.4, 6.9 and $15.7 \%$ for the LEFS, SEFAS, and OMAS respectively (Table 2 ).

Item mean scores were mostly skewed towards the best possible scores across instruments (Table 2). For the LEFS, the lowest scores denoting poorer health were for 'hopping' and the highest scores were for 'walking between rooms'. For the OMAS, the lowest scores were for 'stiffness' and the highest scores were for 'assistive devices'. For the SEFAS the highest scores were for
Table 1 Characteristics of respondents completing the first questionnaire $(n=567)$

\begin{tabular}{|c|c|c|}
\hline & & $\%$ \\
\hline Age years, mean (range) & $57.5(22.2-91.2)$ & \\
\hline Female & 322 & 56.8 \\
\hline \multicolumn{3}{|l|}{ Marital status ${ }^{a}$} \\
\hline Divorced/separated & 77 & 13.6 \\
\hline Cohabitant/married & 379 & 66.8 \\
\hline Single & 47 & 8.3 \\
\hline Widowed & 46 & 8.1 \\
\hline \multicolumn{3}{|l|}{ Education } \\
\hline Under 10 yrs & 157 & 27.7 \\
\hline $10-12$ yrs & 206 & 36.3 \\
\hline University & 181 & 31.9 \\
\hline Body mass index $\left(\mathrm{kg} / \mathrm{m}^{2}\right)$, median range & $27.4(14.4-61.0)$ & \\
\hline Current smoker & 136 & 25.2 \\
\hline Diabetes & 34 & 6.0 \\
\hline \multicolumn{3}{|l|}{ Fracture classification, Weber } \\
\hline A & 15 & 2.6 \\
\hline B & 383 & 67.5 \\
\hline C & 156 & 27.5 \\
\hline \multicolumn{3}{|l|}{ Fracture, clinical features } \\
\hline Uni-malleolar & 294 & 52.5 \\
\hline Bimalleolar & 128 & 22.9 \\
\hline Trimalleolar & 138 & 24.6 \\
\hline \multicolumn{3}{|l|}{ Physical status (ASA classification) } \\
\hline Completely healthy fit & 197 & 34.7 \\
\hline Mild systemic disease & 340 & 60.0 \\
\hline Severe systemic disease, not incapacitating & 30 & 5.3 \\
\hline \multicolumn{3}{|l|}{ Postoperative length of stay in days, median (range) } \\
\hline Surgery duration in minutes, median (range) & $76.0(7-352)$ & \\
\hline Waiting time for surgery in days, median (range) & $5.0(0-68)$ & \\
\hline
\end{tabular}

apercentages do not sum to 100 due to missing data

'getting up from a chair' and the lowest scores were for 'usual pain level'.

Model fit for the unidimensional SEFAS was good according to all criteria (Table 3). The LEFS and OMAS had a RMSEA that was over the criterion of 0.08 . There was support for a bi-dimensional LEFS with scales relating to easy and difficult items. Item-total correlations were over 0.4 for all items with the exceptions of 'assistive devices' and 'use of special innersoles/shoes' for the OMAS and SEFAS respectively (Table 1). Cronbach's alpha ranged from 0.82 to 0.96 for the OMAS and LEFS respectively.

Table 4 shows that there were small but insignificant $(p<0.05)$ score improvements across instruments at retest. Weighted kappa for the individual items indicated 
Table 2 Descriptive statistics, internal consistency $(n=567)$ and reliability $(n=182)$ where all items are coded 0 to 4 for comparison

\begin{tabular}{|c|c|c|c|c|c|c|c|c|c|}
\hline \multirow[t]{2}{*}{ Instrument/item } & \multirow[t]{2}{*}{$\%$ miss } & \multirow[t]{2}{*}{ Mean (SD) } & \multicolumn{5}{|c|}{ Frequencies \% } & \multirow{2}{*}{$\begin{array}{l}\text { Cronbach's alpha } \\
\text { (scale)/item scale } \\
\text { correlation }\end{array}$} & \multirow{2}{*}{$\begin{array}{l}\text { Test-retest ICC } \\
\text { (scores), weighted } \\
\text { kappa (items) }\end{array}$} \\
\hline & & & 0 & 1 & 2 & 3 & 4 & & \\
\hline Lower Extremity Functional Scale LEFS & 4.2 & $67.20(15.09)$ & & & & & & 0.96 & 0.91 \\
\hline LEFS $_{\text {adjusted }}^{c}$ & 2.8 & $83.89(19.01)$ & & & & & & - & 0.91 \\
\hline 1 Usual work, housework, school & 2.6 & $3.51(0.89)$ & 1.8 & 2.5 & 8.2 & 17.5 & 70.0 & 0.81 & 0.77 \\
\hline 2 Hobbies, recreational, sports & 4.9 & $3.22(1.02)$ & 2.8 & 5.4 & 10.2 & 29.8 & 51.8 & 0.78 & 0.76 \\
\hline 3 Getting in and out of bath & 5.8 & $3.54(0.97)$ & 3.4 & 3.2 & 5.1 & 12.4 & 75.9 & 0.72 & 0.76 \\
\hline 4 Walking between rooms & 2.8 & $3.91(0.40)$ & 0.2 & 0.5 & 0.9 & 5.3 & 93.1 & 0.56 & 0.70 \\
\hline 5 Putting on socks or shoes & 3.0 & $3.65(0.72)$ & 0.9 & 1.5 & 4.9 & 17.3 & 75.4 & 0.70 & 0.71 \\
\hline 6 Squatting & 3.0 & $3.03(1.30)$ & 7.8 & 9.1 & 8.0 & 21.7 & 53.3 & 0.73 & 0.74 \\
\hline 7 Lifting things up from floor & 2.1 & $3.82(0.57)$ & 0.9 & 0.5 & 2.2 & 8.0 & 88.4 & 0.61 & 0.79 \\
\hline 8 Light activities in the home & 2.5 & $3.82(0.54)$ & 0.2 & 0.9 & 3.1 & 8.5 & 87.3 & 0.69 & 0.78 \\
\hline 9 Heavy activities in the home & 2.5 & $3.27(1.05)$ & 2.7 & 6.5 & 9.4 & 23.2 & 58.1 & 0.85 & 0.85 \\
\hline 10 Getting in/out of car & 2.5 & $3.72(0.64)$ & 0.2 & 1.6 & 4.4 & 14.2 & 79.7 & 0.67 & 0.68 \\
\hline 11 Walking 2 blocks & 3.0 & $3.69(0.82)$ & 2.4 & 1.5 & 4.4 & 8.2 & 83.6 & 0.74 & 0.80 \\
\hline 12 Walking a mile & 3.4 & $3.42(1.07)$ & 4.2 & 3.8 & 7.9 & 13.7 & 70.3 & 0.82 & 0.84 \\
\hline 13 Going up or down ten stairs & 3.2 & $3.65(0.78)$ & 1.1 & 2.4 & 4.9 & 13.9 & 77.7 & 0.75 & 0.73 \\
\hline 14 Standing $1 \mathrm{~h}$ & 2.8 & $3.11(1.21)$ & 6.0 & 7.8 & 8.6 & 24.0 & 53.6 & 0.84 & 0.85 \\
\hline 15 Sitting $1 \mathrm{~h}$ & 3.4 & $3.77(0.65)$ & 0.5 & 1.8 & 3.1 & 9.5 & 84.8 & 0.51 & 0.57 \\
\hline 16 Running on even ground & 5.1 & $2.74(1.46)$ & 13.6 & 10.3 & 9.9 & 20.7 & 45.5 & 0.85 & 0.87 \\
\hline 17 Running on uneven ground & 4.4 & $2.46(1.47)$ & 16.3 & 12.8 & 13.0 & 24.4 & 33.5 & 0.83 & 0.85 \\
\hline 18 Sharp turns when running fast & 4.9 & $2.53(1.52)$ & 17.1 & 12.5 & 9.3 & 22.0 & 39.1 & 0.84 & 0.82 \\
\hline 19 Hopping & 4.6 & $2.43(1.53)$ & 18.2 & 13.2 & 12.2 & 19.9 & 36.5 & 0.83 & 0.83 \\
\hline 20 Rolling over in bed & 2.7 & $3.82(0.54)$ & 0.4 & 1.1 & 1.6 & 10.0 & 86.7 & 0.56 & 0.65 \\
\hline Olerud-Molander Ankle Score OMAS & 17.3 & $74.12(24.91)$ & & & & & & 0.82 & 0.92 \\
\hline OMAS adjusted $^{c}$ & 1.6 & $75.62(24.07)$ & & & & & & - & 0.91 \\
\hline 1 Pain when walking & 4.9 & $3.01(1.21)$ & 7.3 & 4.8 & 13.8 & 27.6 & 46.6 & 0.67 & 0.76 \\
\hline 2 Stiffness (2 pt. scale) & 2.7 & $1.81(1.99)$ & 54.7 & & & & 45.3 & 0.55 & 0.77 \\
\hline 3 Swelling (3 pt. scale) & 3.5 & $2.83(1.53)$ & 17.1 & & 24.2 & & 58.7 & 0.51 & 0.80 \\
\hline 4 Use of stairs (2 pt. scale) & 1.2 & $3.25(1.03)$ & 1.4 & & 35.8 & & 63.8 & 0.73 & 0.81 \\
\hline 5 Running (2 pt. scale) & 2.5 & $2.66(1.89)$ & 33.6 & & & & 66.4 & 0.66 & 0.81 \\
\hline 6 Jumping (2 pt. scale) & 6.2 & $2.60(1.91)$ & 34.9 & & & & 65.1 & 0.65 & 0.80 \\
\hline 7 Squatting (2 pt. scale) & 4.6 & $2.68(1.88)$ & 33.0 & & & & 67.0 & 0.61 & 0.68 \\
\hline \multirow[t]{2}{*}{8 Assistive devices (3 pt. scale) } & 3.2 & $3.72(0.91)$ & 4.4 & & 5.3 & & 90.3 & 0.37 & 0.90 \\
\hline & & & 0 & 1.33 & & 2.67 & 4 & & \\
\hline 9 Work and daily activities (4 pt. scale) & 2.5 & $3.27(1.14)$ & 6.4 & 5.1 & & 25.8 & 62.8 & 0.66 & 0.77 \\
\hline Self-Reported Foot \& Ankle Score SEFAS & 8.5 & $20.78(9.16)$ & & & & & & 0.93 & 0.93 \\
\hline SEFAS adjusted ${ }^{c}$ & 1.6 & $81.40(19.17)$ & & & & & & - & 0.93 \\
\hline 1 Usual pain level & 1.6 & $2.76(1.51)$ & 2.9 & 14.9 & 19.1 & 29.3 & 33.8 & 0.82 & 0.83 \\
\hline 2 Walking time before pain too much & 3.7 & $3.58(0.83)$ & 0.4 & 5.0 & 5.1 & 14.7 & 74.8 & 0.69 & 0.76 \\
\hline 3 Work not done as carefully as usual & 2.5 & $3.27(0.96)$ & 2.2 & 3.8 & 12.0 & 28.5 & 53.5 & 0.69 & 0.78 \\
\hline 4 Use of special innersoles and shoes & 1.9 & $3.54(1.06)$ & 4.7 & 4.2 & 2.7 & 8.8 & 79.6 & 0.35 & 0.69 \\
\hline 5 Usual work, housework, hobbies & 2.1 & $3.29(0.99)$ & 1.1 & 6.9 & 11.0 & 23.5 & 57.5 & 0.87 & 0.85 \\
\hline 6 Limping & 1.6 & $3.02(1.23)$ & 6.8 & 4.5 & 22.7 & 11.0 & 55.0 & 0.75 & 0.77 \\
\hline 7 Staircase & 2.3 & $3.55(0.80)$ & 0.9 & 2.0 & 8.3 & 18.5 & 70.3 & 0.71 & 0.80 \\
\hline
\end{tabular}


Table 2 Descriptive statistics, internal consistency $(n=567)$ and reliability $(n=182)$ where all items are coded 0 to 4 for comparison (Continued)

\begin{tabular}{|c|c|c|c|c|c|c|c|c|c|}
\hline \multirow[t]{2}{*}{ Instrument/item } & \multirow[t]{2}{*}{$\%$ miss } & \multirow[t]{2}{*}{ Mean (SD) } & \multicolumn{5}{|c|}{ Frequencies \% } & \multirow{2}{*}{$\begin{array}{l}\text { Cronbach's alpha } \\
\text { (scale)/item scale } \\
\text { correlation }\end{array}$} & \multirow{2}{*}{$\begin{array}{l}\text { Test-retest ICC } \\
\text { (scores), weighted } \\
\text { kappa (items) }\end{array}$} \\
\hline & & & 0 & 1 & 2 & 3 & 4 & & \\
\hline 8 Problem in bed & 1.6 & $3.21(1.10)$ & 2.5 & 4.7 & 22.7 & 10.1 & 60.1 & 0.72 & 0.70 \\
\hline 9 Usual free time activities & 1.8 & $3.11(1.09)$ & 2.7 & 9.2 & 10.6 & 29.7 & 47.7 & 0.86 & 0.88 \\
\hline 10 Swelling & 2.1 & $3.00(1.20)$ & 7.1 & 6.9 & 9.4 & 32.4 & 44.3 & 0.57 & 0.90 \\
\hline 11 Getting up from a chair & 1.8 & $3.60(0.72)$ & 0.2 & 1.8 & 7.0 & 19.6 & 71.4 & 0.77 & 0.77 \\
\hline 12 Sudden strong pain & 1.8 & $3.15(1.02)$ & 1.3 & 3.4 & 27.7 & 14.2 & 53.2 & 0.68 & 0.77 \\
\hline
\end{tabular}

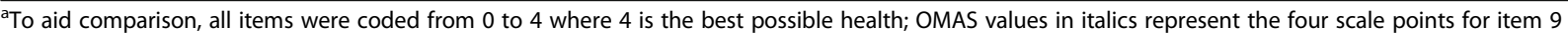
converted to the 0-4 scale. LEFS and SEFAS have five-point scales for all items. OMAS scaling varies across items which gives the blank spaces for those items with four or less scale categories

${ }^{b}$ Instrument scoring: LEFS $0-80$ where 80 is the best possible; LEFS adjusted $0-100$ where 100 is the best possible; OMAS 0-100 where 100 is the best possible health; SEFAS 12-60 where 60 is the worst possible; SEFAS adjusted 0-100 where 100 is the best possible health

${ }^{\mathrm{C}}$ Mean imputation was used when half or fewer items were missing

good agreement between test and retest (Table 2). Intraclass correlations for the scale scores ranged from 0.91 to 0.93 for the LEFS and SEFAS respectively. The use of alternate scoring had little or no effect on ICC levels (Table 2). The SEMs for the adjusted scores which are comparable, ranged from 5.1 to 7.4 for the SEFAS and OMAS respectively (Table 4). The SDC for comparisons of individual patients ranged from 14.1 to 20.6 for the SEFAS and OMAS respectively. The SDC for comparisons of groups of patients ranged from 0.93 to 1.55 for the SEFAS and OMAS respectively.

Table 5 shows that the hypotheses used in validity testing were largely met but some correlations were higher than expected. The lowest correlation between the three ankle instruments was 0.84 (LEFS and SEFAS) and the highest was 0.89 (SEFAS and OMAS). High levels of correlation were found for SF-36 physical functioning scores, the highest being for the LEFS which were comparable to those between the LEFS and other specific instruments. Moderate to high levels of correlation were found for the EQ-5D mobility and pain/discomfort items. For the three instruments, the correlations with the EQ-5D usual activities item were of a similar moderate level and for the remaining two items of self-care and anxiety/depression, of a similar low level. Correlations with the clinical

Table 3 Confirmatory factor analysis tests and goodness of fit indices $(n=567)$

\begin{tabular}{llllll}
\hline Instrument & $X 2$ & $d f$ & CFI $^{\mathrm{a}}$ & TLl $^{\mathrm{b}}$ & RMSEA $^{\mathrm{c}}$ \\
\hline LEFS unidimensional $^{2}$ & 843.4 & 171 & 0.99 & 0.99 & 0.091 \\
LEFS bidimensional $^{d}$ & 604.4 & 169 & 1.00 & 1.00 & 0.073 \\
SEFAS & 165.9 & 54 & 0.99 & 0.99 & 0.063 \\
OMAS & 122.8 & 27 & 0.99 & 0.98 & 0.087 \\
\hline
\end{tabular}

All $\mathrm{X} 2$ tests of model fit were significant with the exception of the LEFS $(p<0.01)$

${ }^{\text {a }}$ Comparative fit index

${ }^{\mathrm{b}}$ Tucker-Lewis Index

${ }^{C}$ Root mean square error of approximation

dLEFS bi-dimensional easy $(1,3-5,7,8,10,11,13,15,20)$ and difficult

$(2,6,9,12,14,16-19)$ items variables were all of a low level, the lowest were for BMI and the highest were for the duration of operation. The use of adjusted scores had very little effect on the size of the correlations.

\section{Discussion}

There was evidence that the LEFS might be bidimensional in this group of patients which contrasts with it is use in applications as a unidimensional measure of lower extremity function. Exploratory factor analysis (data not shown) showed that the items loaded onto two clearly discernible factors relating to easier and more difficult aspects of function which gave better results in the CFA. The LEFS with 20 items, is a good deal longer than the OMAS and SEFAS and such a lengthy instrument that assesses one aspect of health is unusual for PROMs. The OMAS and SEFAS are shorter, have acceptable levels of internal consistency, test-retest reliability and the SEFAS has a lower SEM and hence is more capable of measuring change in individuals and groups of patients.

The current study followed previous studies in treating the LEFS as unidimensional in other aspects of testing but results should be treated with caution until further evidence becomes available. This study is a long-term follow-up of patients and the evidence may be different for patients in the shorter-term post-surgery. LEFS items may differ in their relevance in these patients. For example, more difficult items including 'running', 'squatting' and 'walking a mile' might have greater relevance at follow-up as shown by their much lower ceiling effects compared to the remaining items. The inclusion of easier items in the same scale might mask important effects at follow-up. Eighty percent or more patients had the best possible score on seven LEFS items compared to just one item in each of the OMAS and SEFAS. If long-term outcomes are the focus, then these two instruments might be more responsive to change than the 
Table 4 Standard error of measurement (SEM) and smallest detectable change (SDC) for the three instruments ${ }^{\mathrm{a}}(n=182)$

\begin{tabular}{lllllll}
\hline Instrument & $n$ & Test mean (SD) & Retest mean (SD) & SEM $^{\mathrm{b}}$ & SDC $^{\text {individual }}$ & SDC $^{\mathrm{c}}$ group \\
\hline LEFS (0-80) & 179 & $68.54(15.03)$ & $69.03(15.14)$ & 4.50 & 12.49 & 0.93 \\
LEFS adjusted & 181 & $85.48(18.39)$ & $86.19(18.41)$ & 5.61 & 15.55 & 1.16 \\
SEFAS (12-60) & 172 & $19.70(8.99)$ & $19.49(9.23)$ & 2.39 & 6.62 & 0.50 \\
SEFAS adjusted & 182 & $83.85(18.52)$ & $84.11(19.01)$ & 5.09 & 14.10 & 0.93 \\
OMAS & 140 & $78.04(24.44)$ & $79.64(24.29)$ & 6.87 & 19.04 & 0.92 \\
OMAS adjusted & 176 & $77.66(24.38)$ & $78.85(23.90)$ & 7.41 & 20.55 & 1.55 \\
\hline
\end{tabular}

Instruments scored 0-100 unless otherwise stated

${ }^{\mathrm{b}} \mathrm{Standard}$ error of measurement

'Smallest detectable change

${ }^{b}$ Included for comparison with existing studies that have used the same scoring

unidimensional LEFS. It is recommended that future studies compare the responsiveness to change of these instruments, including treating the LEFS as a bidimensional instrument where evidence supports.

There were low levels of missing data at the item level with very few items having more than $5 \%$ missing. These items tended to relate to more difficult activities undertaken less frequently. Hence, the levels of missing data may reflect uncertainty on the part of the patients regarding their performance, or that they may have held back from undertaking such activities due to concerns about the ankle. Such items include running for the LEFS and jumping for the OMAS. The LEFS item 'getting in and out of bath' denotes low levels of function and had relatively high levels of missing data which may because many Norwegians do not have a bathtub at home.

All items with the exception of the assistive devices items for the OMAS and special innersoles/shoes in the SEFAS, had acceptable item-total correlations. This indicates that these two items might not be adequately contributing to the construct being measured. For example, patients might be using assistive devices, innersoles and shoes for reasons other than the severity of their ankle problem or because of other health problems. These items might be considered for removal if future studies also find that they make a limited contribution in a similar patient population. Cronbach's alpha and test-retest correlations were acceptable for the three instruments. Alpha is dependent on the number of items and hence the highest level was expected for the LEFS.

Scores for the three instruments were highly correlated which is evidence that they are assessing very similar aspects of health and have convergent validity. The highest correlations were found between scores for the OMAS and SEFAS which reflects their ankle specific focus compared to the focus on lower extremity function of the

Table 5 Spearman correlations ${ }^{a}$ between the ankle instrument scores, those for generic instruments and clinical variables $(n=567)$

\begin{tabular}{|c|c|c|c|c|c|c|}
\hline Instrument & LEFS & LEFS Adjusted $^{b}$ & OMAS & OMAS Adjusted & SEFAS & SEFAS Adjusted \\
\hline OMAS & 0.86 & 0.86 & & & & \\
\hline OMAS Adjusted & 0.86 & 0.86 & & & & \\
\hline SEFAS & -0.84 & -0.84 & -0.89 & -0.89 & & \\
\hline SEFAS Adjusted & -0.84 & -0.84 & -0.88 & -0.88 & & \\
\hline SF-36 physical function & 0.85 & 0.86 & 0.76 & 0.77 & -0.74 & -0.73 \\
\hline EQ-5D index & 0.73 & 0.73 & 0.79 & 0.79 & -0.80 & -0.79 \\
\hline Mobility & -0.65 & -0.64 & -0.66 & -0.67 & 0.66 & 0.66 \\
\hline Self-care & -0.35 & -0.36 & -0.32 & -0.33 & 0.34 & 0.34 \\
\hline Usual activities & -0.60 & -0.61 & -0.59 & -0.60 & 0.62 & 0.62 \\
\hline Pain/discomfort & -0.64 & -0.64 & -0.73 & -0.73 & 0.76 & 0.75 \\
\hline Anxiety/depression & -0.30 & -0.31 & -0.30 & -0.31 & 0.31 & 0.30 \\
\hline ASA classification & -0.26 & -0.26 & -0.19 & -0.21 & 0.21 & 0.20 \\
\hline Body Mass Index & -0.15 & -0.16 & -0.21 & -0.19 & 0.14 & 0.15 \\
\hline Duration of operation & -0.24 & -0.23 & -0.25 & -0.26 & 0.24 & 0.22 \\
\hline Uni-, bi-, tri-malleolar & -0.23 & -0.22 & -0.21 & -0.23 & 0.21 & 0.19 \\
\hline
\end{tabular}

aAll correlations are significant $(p<0.01)$

${ }^{\mathrm{b}}$ Adjusted scores where mean imputation is used for missing data when half or more items are completed 
LEFS. These two instruments also had slightly higher correlations with the EQ-5D, including individual EQ-5D items. The LEFS had the highest correlations with SF-36 physical functioning scores and several LEFS items that are not covered by the OMAS and SEFAS, have similar content to this SF-36 scale.

For the LEFS, Cronbach's alpha, test-retest reliability correlation coefficient and the SEM were similar to those previously reported [16]. The OMAS had a slightly higher Cronbach's alpha than in the previous study [17]. The test-retest reliability correlation coefficient was slightly lower and SEM slightly higher than those previously reported [17]. It follows that the smallest detectable change was larger; 19-20 compared to 16 [17]. The SEFAS had a higher alpha and similar level of test-retest reliability compared to the Swedish study that included patients with hind foot and ankle disorders [10]. The SEM and SDC were not reported in this study.

Recommendations for handling missing data were not available for the OMAS. The conventional approach is mean imputation when half or less items are missing. Compared to the approach that has been recommended for the SEFAS [10], this form of imputation increases the number of patients with final scores by $7 \%$. This reduces sample sizes required in evaluative studies including clinical trials. Mean scores and the results of testing were very similar irrespective of the methods of handling missing data. For example, levels of correlation with the EQ-5D scores were virtually unchanged. The conventional approach will reduce sample size requirements in clinical trials and based on these study findings, will increase useable scores by up to $16 \%$ for the OMAS.

Clinicians and researchers selecting PROMs for this group of patients should consider using the SEFAS in preference to the LEFS and OMAS. There is uncertainty surrounding the structural validity of the LEFS, it has greater respondent burden and a broader focus on lower limbs rather than the foot and ankle. The broader focus was reflected in correlations between the LEFS and SF-36 physical function scores which were higher than those between the LEFS, OMAS and SEFAS scores. The OMAS has more complex scoring, performed less satisfactorily than the SEFAS in terms of structural validity and had a higher SEM. The use of mean imputation where half or more items are completed, reduces the number of patients needed for recruitment with negligible effects on measurement properties.

\section{Study limitations}

Important limitations include the follow-up period, potential respondent bias, choice of instruments and lack of testing for other measurement properties. The median time between surgery and questionnaire completion was 4.3 (IQR 3.9-5.1) years [12], and it is important that the measurement properties of the three instruments are assessed at other clinically important follow-up periods. This limitation means that it was not possible to recommend modifications to the instruments including the use of a bi-dimensional LEFS and removal of items across the instruments. The $59 \%$ response rate to the questionnaire is acceptable for this type of study but there were some statistically significant differences between respondents and non-respondents to the questionnaire [12]. Other instruments are available that have undergone limited testing in patients with ankle fracture [5], but respondent burden meant that only three instruments could be included in this study. The design of the study also meant that instrument responsiveness to change could not be assessed. This is an important criterion which further aids the selection of instruments for evaluative studies including clinical trials [11].

Assessment of the SEM and SDC followed the COSMIN checklist [11] and have been previously reported for the LEFS and OMAS [16, 17]. The SDC is the level of change that can be considered real change above measurement error and does not consider whether the change is important. The minimal clinically important difference (MCID) or minimal important change (MIC), are levels of change that patients consider important and further help score interpretation [11]. The MIC has not been reported for the study instruments in this patient population and assessment was not possible within the current study design. It is recommended that the MIC be reported in future studies.

\section{Conclusion}

This is the first study that has concurrently evaluated these instruments in patients following surgery for ankle fracture. Moreover, the LEFS and SEFAS have not been previously evaluated solely in patients with ankle fracture. The three instruments have acceptable evidence for internal consistency, test-retest reliability and construct validity. However, there are some doubts about the unidimensionality of the LEFS in this population and it has a relatively large number of items with the largest ceiling effects representing the highest level of functioning. Further testing of these instruments is recommended in patients with ankle fracture including shorter-term follow-up following surgery. Responsiveness to changes in health should also be assessed with instrument completion taking place before and after an intervention of known efficacy. Instrument content should be carefully considered when choosing between these three instruments. The LEFS is specific to the lower extremities and includes a relatively large number of items. The OMAS is 
designed to be ankle fracture specific and includes clinical weightings whereas the other two instruments are based on simple summed scales. The SEFAS is designed for a range of foot disorders including ankle fractures and has the best measurement properties in this population. Finally, it is recommended that mean imputation is used for missing responses when half or more items are completed by patients.

\section{Abbreviations}

BMI: Body Mass Index; CFA: Confirmatory factor analysis; CFI: Comparative fit index; ICC: Intraclass correlation coefficient; LEFS: Lower Extremity Function Scale; MIC: Minimal Important Change; OMAS: Olerud Molander Ankle Score; ORIF: Open reduction internal fixation; PROMs: Patient reported outcome measures; RMSEA: Root mean square error of approximation; SDC: Smallest detectable change; SEFAS: Self-Reported Foot and Ankle Score; SEM: Standard error of measurement; TLI: Tucker-Lewis Index

\section{Acknowledgements}

The authors thank Meetali Kakad for back-translation of the questionnaires to English.

\section{Funding}

The project was partially funded by The Sophies Minde Foundation and Østfold Hospital. The sponsors had no involvement in study planning, collection, analysis, or interpretation of the data, or in the preparation, or approval of the manuscript.

\section{Availability of data and materials}

The datasets used and/or analysed during the current study are available from the corresponding author on reasonable request.

\section{Authors' contributions}

MGN, US, SEU and KS designed the retrospective cohort study and were responsible for data collection. AMG and KS were responsible for the patient reported outcomes component of the study. AMG performed the statistical analysis and drafted the manuscript. All authors read and approved the final manuscript.

\section{Ethics approval and consent to participate}

All patients received information about the study and gave written consent. The study was approved by the Norwegian Social Science Data Services and the Regional Committees for Medical and Health Research Ethics, Health Region South East.

\section{Competing interests}

The authors declare that they have no competing interests.

\section{Publisher's Note}

Springer Nature remains neutral with regard to jurisdictional claims in published maps and institutional affiliations.

\section{Author details}

${ }^{1}$ Division for Health Services, Norwegian Institute of Public Health, Oslo, Norway. ${ }^{2}$ Department of Orthopaedics, Østfold Hospital, Oslo, Norway. ${ }^{3}$ Department of Orthopaedics, Akershus University Hospital, Lørenskog, Norway. ${ }^{4}$ Institute of Clinical Medicine, University of Oslo, Oslo, Norway. ${ }^{5}$ Department of Pulmonary Medicine, Medical Division, Akershus University Hospital, Lørenskog, Norway. ${ }^{6}$ Health Services Research Unit, Akershus University Hospital, Lørenskog, Norway.

\section{Received: 9 August 2017 Accepted: 19 April 2018}

Published online: 02 May 2018

\section{References}

1. Donken CC, Al-Khateeb H, Verhofstad MH, van Laarhoven CJ. Surgical versus conservative interventions for treating ankle fractures in adults. Cochrane Database Syst Rev. 2012;15(8):CD008470.
2. Somersalo A, Paloneva J, Kautiainen H, Lönnroos E, Heinänen M, Kiviranta I. Incidence of fractures requiring inpatient care. Acta Orthop. 2014;85:525-30.

3. Ma X, Wang X, Huang J, Zhang C, Chen L. Internal fixation of distal tibiofibular syndesmotic injuries: a systematic review with meta-analysis. Int Orthop. 2013;37:1755-63.

4. Van Son MA, De Vries J, Roukema JA, Den Oudsten BL. Health status, health-related quality of life, and quality of life following ankle fractures: a systematic review. Injury. 2013;44:1391-402.

5. Jia Y, Huang H, Gagnier JJ. A Systematic review of measurement properties of patient-reported outcome measures for use in patients with foot or ankle diseases. Qual Life Res 2017; https://doi.org/10.1007/s11136-017-1542-4. [Epub ahead of print].

6. Garratt AM, Schmidt L, Mackintosh A, Fitzpatrick R. Quality of life measurement: bibliographic study of patient assessed health outcome measures. Br Med J. 2002:324:1417-9.

7. Haywood KL, Hargreaves J, Lamb SE. Multi-item outcome measures for lateral ligament injury of the ankle: a structured review. J Eval Clin Pract. 2004;10:339-52.

8. Binkley JM, Stratford PW, Lott SA, Riddle DL. The lower extremity functional scale (LEFS): scale development, measurement properties, and clinical application. North American Orthopaedic Rehabilitation Research Network Phys Ther. 1999;79:371-83

9. Olerud C, Molander H. A scoring scale for symptom evaluation after ankle fracture. Arch Orthop Trauma Surg. 1984;103:190-4.

10. Cöster MC, Bremander A, Rosengren BE, Magnusson H, Carlsson Å, Karlsson MK. Validity, reliability, and responsiveness of the self-reported foot and ankle score (SEFAS) in forefoot, hindfoot, and ankle disorders. Acta Orthop. 2014;85:187-94.

11. Mokkink LB, Terwee CB, Patrick DL, Alonso J, Stratford PW, Knol DL, et al. The COSMIN checklist for assessing the methodological quality of studies on measurement properties of health status instruments: an international Delphi study. Qual Life Res. 2010;19:539-49.

12. Naumann MG, Sigurdsen U, Utvåg SE, Stavem K. Associations of timing of surgery with postoperative length of stay, complications, and functional outcomes 3-6 years after operative fixation of closed ankle fractures. Injury 2017:48:1662-9.

13. Hoogeboom TJ, de Bie RA, den Broeder AA, van den Ende CHM. The Dutch lower extremity functional scale was highly reliable, valid and responsive in individuals with hip/knee osteoarthrtitis: a validation study. BMC Musculoskeletal Disord. 2012;13:117.

14. Dingemans SA, Kleipool SC, Mulders MAM, Winkelhagen J, Schep NWL, et al. Normative data for the lower extremity functional scale (LEFS). Acta Orthop. 2017:88:422-6.

15. Lin CW, Moseley AM, Refshauge KM, Bundy AC. The lower extremity functional scale has good clinimetric properties in people with ankle fracture. Phys Ther. 2009;89:580-8.

16. Repo JP, Tukiainen EJ, Roine RP, Ilves O, Järvenpää S, Häkkinen A. Reliability and validity of the Finnish version of the lower extremity functional scale (LEFS). Disabil Rehabil. 2016;6:1-7.

17. Nilsson GM, Eneroth M, Ekdahl CS. The Swedish version of OMAS is a reliable and valid outcome measure for patients with ankle fractures. BMC Musculoskelet Disord. 2013;14:109.

18. Turhan E, Demirel M, Daylak A, Huri G, Doral MN, Celik D. Translation, crosscultural adaptation, reliability and validity of the Turkish version of the Olerud-Molander ankle score (OMAS). Acta Orthop Traumatol Turc. 2017;51:60-4.

19. Cöster MC, Rosengren BE, Bremander A, Brudin L, Karlsson MK. Comparison of the self-reported foot and ankle score (SEFAS) and the American orthopedic foot and ankle society score (AOFAS). Foot Ankle Int. 2014;35:1031-6.

20. Dolan P. Modelling valuations for EuroQol health states. Med Care. 1997;35:1095-108.

21. Ware JE, Sherbourne CD. The MOS 36-item short-form health survey (SF-36) I: conceptual framework and item selection. Med Care. 1992:30:473-83

22. Bentler P. Comparative fit indexes in structural models. Psychol Bull. 1990:107:238-46.

23. Tucker L, Lewis CA. Reliability coefficient for maximum likelihood factor analysis. Psychometrika. 1973;38:1-10.

24. Browne MW, Cudeck R. Alternative ways of assessing model fit. In KA Bollen \& JS Long (Eds.). Testing structural equation models (pp. 136-162). Newbury Park, CA: Sage, 1993. 
25. Hu L, Bentler PM. Cutoff criteria for fit indexes in covariance structure analysis: conventional critieria versus new alternatives. Struct Equ Model. 1999;6:1-55.

26. Terwee CB, Bot SD, de Boer MR, van der Windt DA, Knol DL, Dekker J, et al. Quality criteria were proposed for measurement properties of health status questionnaires. J Clin Epidemiol. 2007:60:34-42.

27. Fleiss $\mathrm{JL}$, Cohen J. The equivalence of weighted kappa and the intraclass correlation coefficient as measures of reliability. Educ Psychol Meas. 1973;33:613-9.

Ready to submit your research? Choose BMC and benefit from:

- fast, convenient online submission

- thorough peer review by experienced researchers in your field

- rapid publication on acceptance

- support for research data, including large and complex data types

- gold Open Access which fosters wider collaboration and increased citations

- maximum visibility for your research: over $100 \mathrm{M}$ website views per year 